\title{
Ovarian Biometrics and Oocyte Grading Percentage of Yield in Local Goats of Andhra Pradesh
}

\author{
L. Ramsingh ${ }^{1}$, K.Sadasivarao ${ }^{2}$, K.Muralimohan ${ }^{3}$, \\ ${ }^{1,}$ Department of Veterinary Gynaecology\&Obsteritecs, College of Veterinary Science \\ ${ }^{2}$,Sri Venkateswara Veterinary University, Rajendranagar, Hyderabad - 500030 (A.P.) INDIA. \\ '. Assistant Professor, Dept. of VGO, CVSc, Rajendranagar, Hyderabad
}

\begin{abstract}
The present study was undertaken to assess the relative efficiency of three different collection techniques of ovarian biometrics and oocytes grading percent of oocytes in local goats of Andhra Pradesh The mean oocyte recovery from right and left ovary was $1.9 \pm 0.28$ and $0.8 \pm 0.18$ in aspiration technique, $2.15 \pm$ 0.31 and $2.9 \pm 0.46$ in dissection technique and $6.55 \pm 0.57$ and $4.51 \pm 0.46$ in slicing technique. The mean oocyte recovery rate was $1.5 \pm 0.22$ and $1.0 \pm 0.33$ under aspiration technique, $2.58 \pm 0.47$ and $2.43 \pm 0.36$ under dissection technique and $5.26 \pm 0.46$ and $6.3 \pm 0.71$. The correlation of oocyte recovery in aspiration with length, width, thickness and weight was 0.16, 0.10, 0.19 and 0.11, respectively. Slicing techniques showed a correlation with length (0.25), width (0.43), thickness (0.26), and weight (0.09). The values of correlation coefficient of oocyte recovery in dissection techniques with ovarian biometrics were length $(0.01)$, width $(-0.04)$ thickness (-0.03), weight (-0.003). The mean numbers of oocytes of different grades recovered were $0.34 \pm 0.03$, $0.62 \pm 0.07$ and $1.37 \pm 0.09$ in aspiration, dissection and slicing techniques, respectively. Among the different grades of oocytes, significantly higher per cent of 'A' (27.78) and ' $B$ ' (38.89) grade oocytes were retrieved by aspiration and dissection technique when compared to slicing technique. With respect to 'C' and ' $D$ ' grade oocytes, significantly higher numbers of oocytes were retrieved by slicing technique than the aspiration and dissection techniques. Out of 437 oocytes retrieved in the present study, significantly higher per cent (50.57) yield was by slicing technique, followed by dissection technique (37.07) and aspiration (12.53).
\end{abstract}

Key Words: Oocyte grading, Aspiration, Dissection, Slicing, Ovarian biometrics, Goat

\section{INTRODUCTION}

Reproduction is the basic field of live stock production. The genetic improvement of live stock can be obtained by maximum utilization of proven sires and dams by following the artificial insemination and Embryo Transfer Technology (ETT). Follicular oocytes could be matured in vitro and used for in vitro fertilization for producing large number of embryos (Agarawal, 1992 and Suzuki et al., 1992). In vitro techniques are powerful tools for studying physiology of maturation, fertilization, development of pre-implantation embryos and increasing production as it gives access to micromanipulation of embryos. For such studies, a large number of in vitro produced embryos are needed, which in turn need larger number of oocytes only. The total number of oocytes obtained per ovary is varied with different techniques. Therefore, for efficient in vitro production of embryo from ovaries procured from abattoirs is necessary to develop technique that can maximize the oocyte recovery. In case of the goat, the first birth using the IVF procedure on ovulated oocytes was achieved by Hanada (1985) and in the last few years, many studies on in vitro maturation and IVF of goat oocytes were conducted.

\section{Materials And Methods}

The present study was undertaken during February to October months on local goat breeds that were maintained by the shepherd of Andhra Pradesh. A total number of 120 non-gravid genitalia of local does were collected immediately after slaughter at municipal slaughter house and transported to the laboratory within $2 \mathrm{hr}$ in a thermos at $34^{\circ} \mathrm{C}$ in normal saline $(0.9$ per cent) containing gentamicin $(50 \mu \mathrm{g} / \mathrm{ml})$. The genitalia were washed with tap water thrice and the ovaries were separated. The separated ovaries were sorted as left and right ovaries and washed separately with DPBS (pH 7.3) containing gentamicin $(50 \mu \mathrm{g} / \mathrm{ml})$.

Biometrics: The length, width and thickness of ovaries were measured with the help of vernier calipers. The distance from the anterior to posterior end of the ovary was considered as the length of the ovaries. The labeled ovaries (right and left) were weighted to the nearest milligram the help of electronic digital balance.

Oocyte Recovery: The oocytes were collected aseptically from the ovaries by three methods: 
(1) Aspiration: The visible follicles present on the surface of the ovary were aspirated with $22 \mathrm{G}$ needle fixed to $5 \mathrm{ml}$ disposable syringe containing 1-2 $\mathrm{ml}$ of DPBS. The goat oocytes were aspirated from individual ovaries after carefully removing the extraneous tissue and were placed in petri dish containing $1 \mathrm{ml}$ of DPBS for grading.

(2)Dissection Technique:The ovaries were placed in a sterile glass petri dish containing $2 \mathrm{ml}$ of DPBS. All the visible follicles were carefully subjected to blunt dissection with the help of forceps and the remaining ovarian tissue was removed after a brief rinsing. The follicles were ruptured and the follicular fluid was allowed to flow into the DPBS.

(3)Slicing: The ovaries were held firmly with the help of forceps in a sterile glass petri dish containing $2 \mathrm{ml}$ of DPBS. The ovaries were sliced into possible thin sections with a blade fixed to the artery forceps. The oocytes containing DPBS media were transferred to the petridish and observed under Stereozoom microscope to grade the oocytes. The petri dish was observed under Stereozoom microscope and the oocytes were transferred to a searching dish containing DPBS for grading.

\section{Grading of oocytes}

Oocytes were classified on the basis of cumulus layer as fallows (Singh and Sharma 1991).

\begin{tabular}{|l|l|l|}
\hline. No. & Number of cumulus layers present & Grade \\
\hline 1 & More than three layers of cumulus cells & A \\
\hline 2 & One to two layers of cumulus cells & B \\
\hline 3 & Scattered cumulus complex & C \\
\hline
\end{tabular}
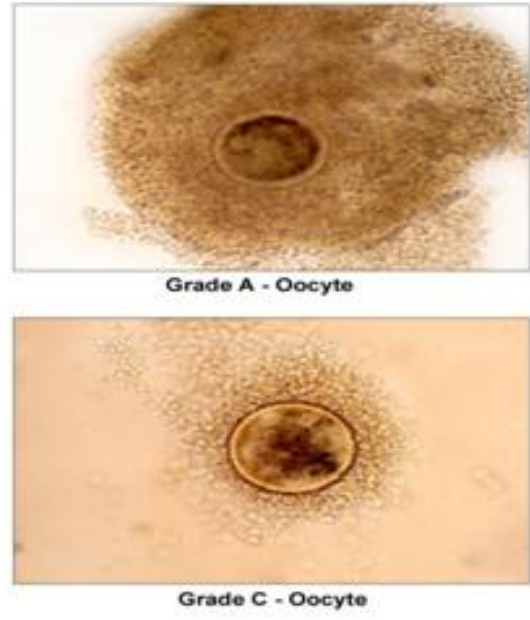

Fig.5: Figures of A,B,C and D Grade Oocytes in non descriptive does
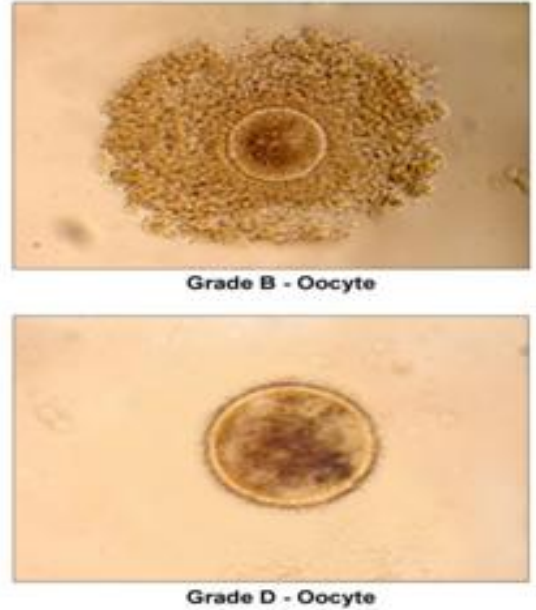

Grade B - Oocyte

\subsection{Biometrics of ovaries:}

III. Results And Discussion

The length, width and thickness of the right and left ovaries were $1.54 \pm 0,03$ and $1.54 \pm 0.04,1.17 \pm$ $0.03 \mathrm{~cm}$ and $1.4 \pm 0.03 ; 0.80 \pm 0.02$ and $0.82 \pm 0.03 \mathrm{~cm}$, respectively. There were no differences between right and left ovaries in terms of length and thickness. The weights of the right and left ovaries were $0.91 \pm 0.06$ and $0.93 \pm 0.07$ without any significant differences which is in agreement with the studies of Ijapuriet al. (1999) and Adigwe and Fayemi (2005), andAdiqwe and Fayemi (2005). The variation in the biometrics might be attributed to breed, season and nutrition.

\subsection{Oocyte retrieval:}

The number of oocytes retrived was significantly higher in slicing method $(5.52 \pm 0.40)$, followed by dissection $(2.52 \pm 0.28)$ and aspiration (1.35 \pm 0.18$)$. Similar techniques were also employed by Waniet al., (2000), Suresh Kumar et al. (2000), (2001), Gogoiet al. (2001) and Shirigiet al. (2005) with variable number or per cent of oocytes retrived in the ovaries of small ruminants. The different A, B, C and D grades of oocytesretrived from left and right ovaries under aspiration, dissection and slicing techniques were not significantly differed between the numbers of oocytes except in "B" grade oocyte, significantly higher number 
was retrieved from right ovary under slicing technique.The yield of grade 'A' oocytes was not significantly differed between techniques except in slicing, The retrieval of grade "B" oocyte was significantly higher in dissection and slicing techniques rather than aspiration in the left ovary, while, significantly higher number was retrived in slicing technique. The retrieval of oocytes of grades ' $C$ ' and ' $D$ ' significantly higher in slicing techniques only, from both left and right ovaries.The present yield of oocyte was significantly higher in slicing (50.57) followed by dissection (37.52) and aspiration (20.70) techniques. However, there was nolike wise, significantly higher per cent of A, B, C and D grade oocytes were retrived in slicing techniques when compared to aspiration and dissection techniques.Lorenzo et al. (1999) and recorded similar trend in per cent of oocyte retrieval Kumaret al. (2000), but vice versa was noticed by Bondeet al. (2000).

\subsection{Percent yield of oocytes}

In the present study, B grade oocytes were retrieved to a greater (per cent) by aspiration (12.53), dissection (37.07) and slicing (50.57), while the recovery of grade D was found lowest by all the techniques. The aspiration technique also yielded grade $\mathrm{A}$ oocytes to a greater extent. The grade $\mathrm{C}$ oocytes were recovered to a greater extent by slicing technique. The overall yield was highest with slicing technique,. The oocytes remain firmly attached to the small and medium sized follicles before cumulus expansion and cannot be aspired, but can be easily recovered from the small follicles when the slicing method is employed. Slicing of ovaries is a simple and efficient tool for recovering good quality oocytes, but the aspiration technique is laborious and time consuming. These reports also confirm the report of Pawsheet al. (1994). The grade A and B oocytes were retrieved greatly from aspiration technique and dissection technique when compared to grade $\mathrm{C}$ and $\mathrm{D}$ oocytes; the latter were recovered to a greater extent by slicing method. These findings were in confirmation with the report of Gogoiet al. (2001). From the results of the present study,. The maximum per cent yield of grade A and $\mathrm{B}$ oocytes was observed by aspiration technique and dissection technique, while the grade $\mathrm{C}$ and $\mathrm{D}$ oocytes were retrieved by slicing technique. Overall yield of oocytes was highest with slicing technique when compared to the other techniques.

\section{References}

[1] Adigwe P.I and Fayemi O A biometric 2005 Study of the reproductive of the Red Sokoto (maradi) goats of Nigeria. Pakistan Veterinary Journal 25: 149-150

[2] Agarawal KP 1992 In vitro maturation of caprineoocytes.Indian journal of Animal reproduction 13 (2): 195 - 197.

[3] Bonde SW, Naqvi SMK and Mittal JP 2000 Comparison of oocyte recovery from surface follicles of sheep and goat ovaries.International Journal of Animal Sciences 15: 1-4.

[4] Das GK, Manjumdar AC, and Gupta S.K 1996 Study of collection techniques on oocyte recovery and quality in goat. International Journal Animal Science 11: 143-144.

[5] Gogoi A K, Borgohain B N, Deka B C and Chakravarthy P, 2001 Comparative efficacy of aspiration and dissection techniques on the recovery of oocytes from goat ovaries. Indian Journal of Animal Reproduction 22: 19-22.

[6] Hanada A 1985 Invitro fertilization in goats.Japan Journal of Animal Reproduction 31: 21 -26.

[7] Ijapure K.P, Singh B.K, and Chouhan R.A.S 1999 Biometrical studies of Reproductive organs of she goats (Capra hircus). Indian Veterinary Journal 76: 353-354.

[8] Lorenzo PL, Calduch T, Illera MJ, Illera JC, Picazo RA and Illera M, 1999 Study of the ultra-structural morphology of sheep oocytes collected for in vitro maturation and fertilization. Medicinaveterinaria 16: 196-201.

[9] Pawshe CH, Totely SM, and Jain SK, 1994 A comparison of three methods of recovery of goat oocytes for invitro maturation and fertilization.Theriogenology42 $111-125$.

[10] Shirazi A, Shams-Esfandabadi N and Hosseini SM 2005 A comparison of two recovery methods of ovine oocytes for in vitro maturation. Small Ruminant Research 58: 283-286.

[11] Singh R B and Sarma A 1991 Importance of cumulus mass in the maturation of goat oocytes under in vitro conditions. National Symposium and $7^{\text {th }}$ Annual Conference of Society of Animal Physiologists of India, Madras.Pp 30.

[12] Suresh Kumar, Maurya SN and kumar S 2000 Evaluation of oocyte retrieval methods from bubaline ovaries.Indian Journal of Animal Research 34: 130-132.

[13] Suzuki T, Singh S K, Sujata I and Madam M L 1992 In vitro fertilization of water buffalo follicular oocytes and their ability to cleave in vitro. Theriogenology 38: 1187-1194.

[14] Wani NA, Wani GM, Khan MZ and Salahudin S 2000 Effect of oocyte harvesting techniques on in vitro maturation and in vitro fertilization in sheep.Small Ruminant Research 36: 63-67. 